This item was submitted to Loughborough's Research Repository by the author.

Items in Figshare are protected by copyright, with all rights reserved, unless otherwise indicated.

\title{
The internationalization of National Biomechanics Day
}

\section{PLEASE CITE THE PUBLISHED VERSION}

https://doi.org/10.1016/j.jbiomech.2019.03.030

\section{PUBLISHER}

(C) Elsevier BV

\section{VERSION}

AM (Accepted Manuscript)

\section{PUBLISHER STATEMENT}

This paper was accepted for publication in the journal Journal of Biomechanics and the definitive published version is available at https://doi.org/10.1016/j.jbiomech.2019.03.030.

\section{LICENCE}

CC BY-NC-ND 4.0

\section{REPOSITORY RECORD}

Shultz, Sarah P., Felipe Carpes, Laura-Anne Furlong, Scott Landry, and Paul DeVita. 2019. "The Internationalization of National Biomechanics Day". figshare. https://hdl.handle.net/2134/37550. 


\section{Accepted Manuscript}

The Internationalization of National Biomechanics Day

Sarah P. Shultz, Felipe Carpes, Laura-Anne Furlong, Scott Landry, Paul DeVita

PII:

S0021-9290(19)30210-6

DOI:

https://doi.org/10.1016/j.jbiomech.2019.03.030

Reference:

BM 9128

To appear in:

Journal of Biomechanics

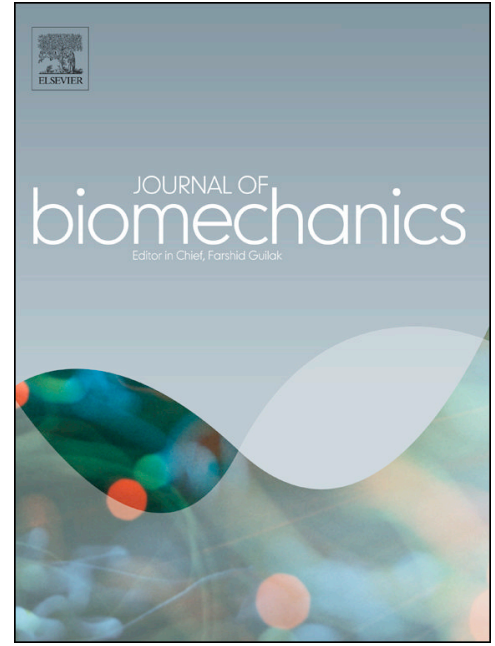

Accepted Date: $\quad 23$ March 2019

Please cite this article as: S.P. Shultz, F. Carpes, L-A. Furlong, S. Landry, P. DeVita, The Internationalization of National Biomechanics Day, Journal of Biomechanics (2019), doi: https://doi.org/10.1016/j.jbiomech.2019.03.030

This is a PDF file of an unedited manuscript that has been accepted for publication. As a service to our customers we are providing this early version of the manuscript. The manuscript will undergo copyediting, typesetting, and review of the resulting proof before it is published in its final form. Please note that during the production process errors may be discovered which could affect the content, and all legal disclaimers that apply to the journal pertain. 


\section{The Internationalization of National Biomechanics Day}

Authors:

Sarah P. Shultz, Ph.D.

Department of Kinesiology, Seattle University, Seattle, WA 98122 Felipe Carpes, Ph.D.

Federal University of Pampa, Uruguaiana, Brazil Laura-Anne Furlong, Ph.D.

Department of Exercise and Sport Sciences, Loughborough University, Loughborough, U.K.

Scott Landry, Ph.D.

Department of Kinesiology, Acadia University, Nova Scotia, Canada, B4P2R6 Paul DeVita, Ph.D.

L.T. Walker Distinguished Professor of Kinesiology, Department of Kinesiology, East Carolina University, Greenville, NC 27858

Corresponding Author:

Paul DeVita

Email: devitap@ecu.edu

Phone: 252 - 737 - 4563 


\begin{abstract}
National Biomechanics Day (NBD) was initiated in 2016 as a nation-wide effort to introduce Biomechanics to high school students throughout the United States. After that initial year, many people around the world joined NBD to promote Biomechanics in their own countries. National Biomechanics Day became international. We describe NBD procedures and events in four of these countries with the intent of demonstrating mechanisms that may enable Biomechanists around the world to successfully join the NBD celebration.
\end{abstract}

\title{
INTRODUCTION
}

We created National Biomechanics Day (Website: Link 1) in 2016 as a nationwide initiative to increase the impact of Biomechanics in the United States. Our mechanism for achieving this goal was and remains introducing Biomechanics to high school students, a population largely under-exposed to Biomechanics science. We propose through increased awareness among young people, more professionals will create careers in Biomechanics and these Biomechanists will expand the many valuable contributions Biomechanics already makes to human society.

NBD has experienced phenomenal growth since 2016 along several important avenues. We have expanded from two sponsors in 2016 to 31 and counting in 2019. Our sponsors include many Biomechanics societies, instrument manufacturers, and commercial entities using Biomechanics to create their products and services. Most importantly the growth in the number of participating Biomechanics sites, Biomechanists, and high school students has exceeded our expectations. NBD 2016 had 48 events, 176 Biomechanists, and 2,026 high school students. This 
past year we had 151 events, 539 Biomechanists, and over 11,000 students enjoying Biomechanics demonstrations around the world. In our three years, we have introduced Biomechanics to over 20,000 high school students. Our tremendous growth has been due to the expansion of National Biomechanics Day to a worldwide, international celebration of Biomechanics and this expansion was driven by the enthusiasm of Biomechanists around the world. In this essay we highlight the international expansion of NBD through activities in four exemplar nations.

New Zealand (NZ) university researchers collaborated to engage over 2500 secondary school students and teachers nationally. Our success is due to several unique approaches to NBD:

Use the buddy system. From the beginning, a collaborative consortium was created with representatives from six universities, along with a secondary school teacher who consulted on the needs of students and teachers. The consortium created a community for coordinating activities and periodic meetings helped to organize each site prior to the event.

Find support. The financial support received from the Ministry of Business, Innovation and Employment (Unlocking Curious Minds MAUX 1607, 1710) was integral to NBD success in NZ. In-kind sponsorship from transportation and marketing companies heavily discounted costs. Industry partners like Logemas, IMeasureU, Silicon Coach, and Weta Workshop provided expert resources, equipment, and software, which improved the student experience.

Think beyond the lab. The consortium was aware of interest from schools located too far away from university sites. In 2016, we produced a live streaming video demonstration from the university labs, which engaged 14 additional schools. In 2017, we partnered with industry sponsor, Silicon Coach, to create a biomechanics scavenger hunt through facebook, which 
included a series of biomechanics tasks completed in a timed race; the winning school received a prize from Silicon Coach. Online engagement is an effective tool for universities to participate in NBD despite little or no access to lab resources.

Work to your strengths. Each biomechanics lab is unique. While working together, each site sought distinct identities. Auckland University of Technology invited professional basketball players to emphasize their ties to high performance sport, Auckland Bioengineering Institute demonstrated high tech tissue modeling, and Massey University's two locations highlighted ties to veterinary and creative industry. University of Waikato emphasized their partnership with the Home of Cycling, University of Canterbury engaged students in research using informal sports performance measures, and University of Otago used their flume to demonstrate aquatic biomechanics. The activities at each university ranged in levels of technology and were dependent on the resources available.

Be efficient. Engagement can be fun and rewarding but is often time-consuming. In 2018, the consortium worked collaboratively with Virginia Tech researchers to pilot an alignment of research and engagement, The Big Experiment, sponsored by IMeasureU and Logemas. Ethics approval was obtained and preparations made to understand the capacity to collect research quality data while participating in NBD. The project successfully collected anthropometric, physical activity and jump height data from 500 students in a 24 hour period.

The lessons learned and our ability to work collaboratively have expanded the possibilities of what NBD can accomplish in NZ.

Brazil also joined the international NBD initiative in 2017 and did so through the Brazilian Society of Biomechanics (BSB Website Link 2). In 2019, NBD will have a special 
session at the XVIII Brazilian Congress of Biomechanics with all NBD promoters being invited to show activities they performed as part of the past NBDs.

Despite challenges in bringing young students to the university due to deficits in city public transportation, limited budgets for the activities, and resistance of some families to let their children travel to a university without parents, NBD brings many benefits. It is an opportunity to engage lab students in promoting their research and translating science into an accessible language to the general population. NBD is an opportunity to give back to the society a portion of the investment the country makes in education and science. Furthermore, it is a chance to increase young people's interest in science and biomechanics, the true heart on NBD.

While performing activities in the lab, most of the Brazilians groups engage visitors as research participants, which means conducting some simple data collection to demonstrate biomechanics procedures. Another initial strategy is to give a general idea of the nature of biomechanics, demonstrate research techniques and instruments, and then provide time for questions from the visitors. It is important to consider questions related to the local reality, which enables the visitor to more easily follow the ideas and better understand the applications of biomechanics. BSB suggests show biomechanics to both students and their families, to more fully valorize the science, the importance of the university to the community, and increase interest of other family members in biomechanics. Brazilian activities also included traveling demonstrations, generally with less instrumentation, for schools having difficulty transporting students to the local universities. We invite the reader to view photographs and videos (Link 3) from activities performed in different universities in Brazil.

Additionally, BSB motivates biomechanics groups to use NBD as a strategy to increase the interest of young students to join the university. Young people in Brazil sometimes leave 
school prior to graduation work and support their families. NBD is a chance to show to young boys and girls that investing part of their time in 4-5 years of study will have a major impact on their future. Therefore, in the end NBD is not only about biomechanics, it is about providing an experience that can impact on the whole life of the students.

Evolution, organization, and timing are the underlying features of the development of NBD in the UK and Ireland. NBD has steadily evolved from two participating laboratories in 2017 (University of Wolverhampton and Loughborough University) to an increasingly diverse six-week event highlighting the vast width of the discipline, kicking off with British Science Week in March. Biomechanists in research and industry have delivered talks to schoolchildren, conducted lab visits, delivered public lectures, invited the public to test their rugby scrummaging technique, and battled it out to be the best Biomechanics Charades Lab of 2018. Events span the clinical and sporting realms in both universities and industry, with insightful, well received videos created by the English Institute of Sport (Link 4) (Click Link 5, Link 6 and Link 7). 2019 events are looking to be bigger, better, and even more diverse, with the 2019 Clinical Motion Analysis (Link 8) challenge seeking a 'Strictly Come Dancing' champion, and the Royal Veterinary College hosting a night with the dinosaurs (Link 9).

Working with institutional outreach and marketing teams to deliver events is encouraged, as these teams already have the contacts, planning, and monitoring processes required to deliver large- and small-scale outreach events. Importantly, they can leverage internal funding support. They are also aware of institutional strategic priorities and other upcoming events, so can advise on not only how to deliver a day, but also when. The importance of working to your strengths and what your lab is known for is critical. Students come to Loughborough (Link 10for 3.5 hours to learn about biomechanics, motor control, and muscle function as applied to elite sports 
performance and technology. Sessions are adaptations from existing undergraduate laboratories and research projects. Our modus operandi is not focusing on intricate details or promotion of ongoing research, but inspiring students to go home and investigate Biomechanics-related questions. We utilize existing online resources (e.g. the Two Minute Tweet videos Link 11 from the International Society of Biomechanics in Sports) and do short presentations from current faculty highlighting the many different routes into, and reasons for engaging with, biomechanics. This is an easily adaptable model for organizing both large and small-scale events.

Timing of various NBDs is critical to our success. The biomechanics team at University of Bath host their event as part of British Science Week in mid-March - a Rugby Union research showcase conveniently occurring on the final day of the Six Nations competition. This builds on significant public interest in the game at this time. Organizing NBD in April is highly appropriate for those working in amputee gait and rehabilitation as it coincides with Limb Loss Awareness Month in both the UK and US. It provides an opportunity to organize an NBD event which may take the form of a lab visit or alternatively, a public lecture or seminar to interested local populations. An excellent event in this area was organized at the University of Southampton with Paralympian Aaron Phipps in attendance. While NBD has a particular, official date each year, to make the most of timing, sites organize events across a six-week period from March through April.

Many Canadian universities and colleges have strived for years to engage and expose middle school and high school students to the fascinating world of Biomechanics. As part of these efforts and spanning almost 5,000 kilometers, NBD was officially celebrated from the West (Douglas College) to East (Acadia University) coasts of Canada in 2018. The NBD 
initiative is certainly picking up "STEAM" and it will be an important priority within Canada in 2019 and beyond.

In 2018 through social media (e.g. Twitter Link 12 and Facebook Link 13), NBD was a major promoter of the $20^{\text {th }}$ biennial meeting of the Canadian Society for Biomechanics in Halifax during August. In response, CSB 2018 prioritized publicizing and encouraging attendees to officially register and take part in future NBD events. The 2019 annual Ontario Biomechanics Conference is being held at the University of Windsor and an AGM agenda item will develop strategies that Ontario, and Canada for that matter, can employ to elevate the profile of NBD for more high school students.

For NBD 2018, several exciting initiatives were undertaken within Canada to introduce Biomechanics to high school students. The Human Performance Laboratory in Calgary, for example, hosted approximately 500 high school students as part of their open house and NBD celebration and this event had graduate students and post docs leading approximately 30 different demonstrations and research stations, primarily focused on biomechanics. Also celebrating NBD, Douglas College in British Columbia had high school students analyze a golf swing, walking in high heels and the, “oh so very popular," Floss Dance. The students, along with Douglas College's President, had their posture analyzed and 30 undergraduates did interactive presentations on topics such as wheelchair propulsion and balancing on the bosu ball. The University of Saskatchewan had 15 graduate students and 7 faculty from three Colleges (Medicine, Engineering and Kinesiology) host an NBD 2018 event for almost 50 high school students. The students learned about lifting tasks, prosthetic limb design, mechanical testing machines and how to analyze CT bone scans (Click Here Link 14). In Central Canada, Queen's University introduced high school students to qualitative and quantitative analyses of 
biomechanical data through Dr. Niko Troje's online BML Walker Demo (BML Walker Demo

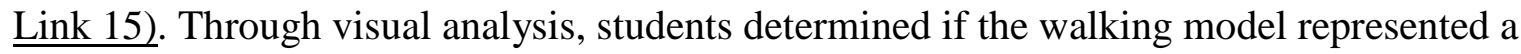
person who was either male/female, happy/sad or heavy/light. Students devised instructions on how to encourage a person to jump the highest, and spent time investigating the vertical force profiles of five common activities. On the Canadian East Coast, almost 150 high school students attended demonstrations at Acadia University's mLAB throughout the month surrounding NBD 2018. Students interacted with a real-time Visual3D motion capture model and learned about the important role Biomechanics has in computer guided surgery. They were also shown how footwear companies develop and test products (lick Here). Hosting and promoting Canadian NBD events, like the examples highlighted above, are important initiatives in continuing to expose Canadian high school students to the massive impact that Biomechanics is having within Canada and beyond.

We are excited about the future of Biomechanics and we continue to propose the idea that Biomechanics will be the breakthrough science of the $21^{\text {st }}$ century, as we explained last year (DeVita, 2018). National Biomechanics Day is enjoyed around the world because it is a unifying platform upon which we coalesce into one grand celebration of our science. We encourage all Biomechanists in all Biomechanics fields to join National Biomechanics Day and help us expand the many beneficial outcomes of the practice of Biomechanics.

Acknowledgements

NBD gratefully acknowledges its 33 current sponsors (Link 14) for their continued support. We also acknowledge the work of Jeroen Aeles, Ph.D., Geoff Handsfield, Ph.D., Matej 
Daniel, Ph.D. for leading national efforts to grow NBD in Australia, New Zealand, and the Czech Republic.

References

DeVita, P., 2018, Why National Biomechanics Day? J. Biomech. 71, 1-3.

List of Links

1. http://nationalbiomechanicsday.asbweb.org/

2. http://www.bsb.org.br/

3. https://www.dropbox.com/sh/ghkhq7zadroteo5/AAB9OqgH089aDTLAzbvVkVQa?dl=0

4. https://www.eis2win.co.uk/

5. https://www.youtube.com/watch?v=PPcp7CLAXBA

6. https://www.youtube.com/watch?v=PPcp7CLAXBA

7. https://www.youtube.com/watch?v=pJB_wGRtvbA

8. https://cmasuki.org/

9. https://dawndinos.com/

10. https://about.imascientist.org.uk/2018/what-laura-anne-furlong-did-with-her-prize$\underline{\text { money/ }}$

11. https://www.youtube.com/watch?v=gMZGoKrwuBI

12. https://twitter.com/BiomechanicsDay

13. https://www.facebook.com/BiomechanicsDay/ 
14. https://acadiaumy.sharepoint.com/:f:/g/personal/scott_landry_acadiau_ca/EgH0hmu5nmZCnrVfCgsSj6 oByqd-cVNN2vb608DSRB6nYw?e=h6pEwt

15. https://www.biomotionlab.ca/html5-bml-walker/ 